\title{
Synthesis and Photochromism Studies of 1-[3,5-dimethyl-4-isoxazolyl]-2-[2-methyl-5-acetenyl-3-thienyl] Perfluorocyclopentene
}

\author{
Nian-Sheng WANG ${ }^{1, a}$, Ren-Jie WANG ${ }^{2, b,{ }^{*}}$, Xiao-Xia ZHANG ${ }^{3, c}$ \\ Jiangxi Key Lab of Organic Chemistry, Jiangxi Science and Technology Normal University, \\ Nanchang, 330013, China \\ *bio-wrj@163.com
}

Keywords: Diarylethene, Photochromic, Fluorescence, Isoxazolyl.

\begin{abstract}
A new unsymmetrical photochromic diarylethene 1- [3,5-dimethyl-4-isoxazolyl] -2-[2-methyl-5-acetenyl-3-thienyl] perfluorocyclopentene has been synthesized. Its photochromic in hexane solution and kinetics experiment were investigated in detail. The result indicated that this diarylethene had reversible photochromism, changing the color from colorless to purple in hexane solution upon appropriate irradiation with UV, respectively.
\end{abstract}

\section{Introduction}

Photochromic compounds have been extensively investigated due to their potential applications in optical switches and memories [1]. Up to now, various types of photochromic compounds, such as spirobenzopyrans [2], azobenzenes [3], fulgides [4], and diarylethenes [5], Among various organic photochromic compounds, diarylethene derivatives are regarded as the best promising candidates because they have notable thermal irreversible photochromic behaviour [6] and remarkable fatigue resistance [7], which make them promising for the application in optical memory devices, displays, molecular sensors, and photoactuators [8,9]. It is well known that diarylethenes can reversibly transform from the open-ring isomers to the close-ring isomers upon irradiation with UV light, and their physicochemical properties mainly depend on several factors, such as the categories of heterocyclic moieties, substituents and extension of $\mathrm{p}-\pi^{*}[10,11]$. For example, Shoji et al. introduced alkyl substituents at the reactive positions of the oxidized dithienyl diarylethenes, which could efficiently accelerate the thermal fading reaction, while introduction of a methyl group at the 4-position of thiophene ring could accelerate the formation of thermal byproducts [12].

In this work, we synthesized a new unsymmetrical diarylethene 1-[3,5-dimethyl-4-isoxazolyl] -2-[2-methyl-5-acetenyl-3-thienyl] perfluorocyclopentene (10). The synthetic route and the photochromic scheme for $\mathbf{1 0}$ are shown in Scheme 1.

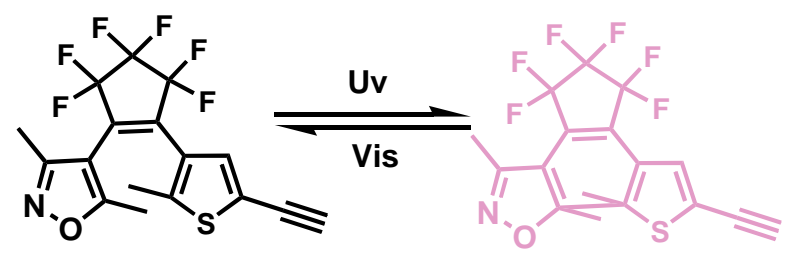

Scheme 1. Photochromism of 10.

\section{Experiments}

The synthesis route for 10 was shown in Scheme 2. NMR spectra were recorded on Bruker AV400 (400 MHz) spectrometer with $\mathrm{CDCl}_{3}$ as the solvent and tetramethylsilane as an internal standard. The structure of 10 were confirmed by ${ }^{1} \mathrm{H}$ NMR (400 MHz, $\mathrm{CDCl}_{3}, \mathrm{TMS}$ ): 1.95 (d, $6 \mathrm{H}, J=8.0 \mathrm{~Hz},-\mathrm{CH}_{3}$ ), 2.13 (s, 3H, $-\mathrm{CH}_{3}$ ), 3.30 (s, 1H, $\left.-\mathrm{C} \equiv \mathrm{CH}\right), 7.14$ (s, 1H, thienyl-H). 


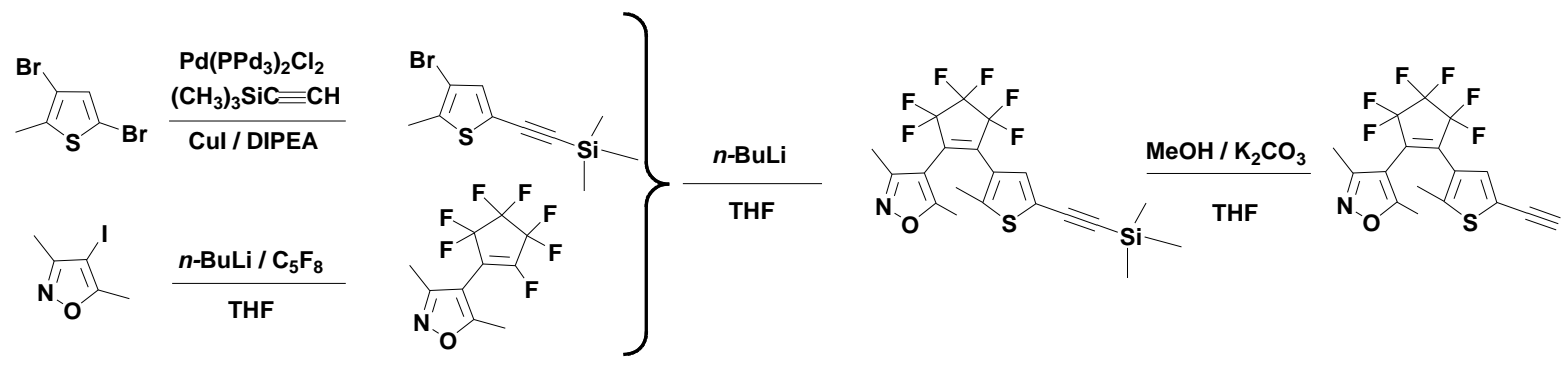

Scheme 2. Synthetic route for 10.

\section{Results and Discussion}

\section{Photochromism of 10}

The photochromic behaviors of $10\left(2.0 \times 10^{-5} \mathrm{~mol} \mathrm{~L}^{-1}\right)$ induced by photoirradiation were measured in hexane at room temperature. As shown in Fig 1, 10 exhibited a sharp absorption peak at 255 ( $\varepsilon=$ $1.56 \times 10^{4} \mathrm{~L} \mathrm{~mol}^{-1} \mathrm{~cm}^{-1}$ ) $\mathrm{nm}$ due to a $\pi-\pi^{*}$ transition. Upon irradiation with $297 \mathrm{~nm}$ light, a new visible absorption band was observed at $515\left(\varepsilon=2.07 \times 10^{4} \mathrm{~L} \mathrm{~mol}^{-1} \mathrm{~cm}^{-1}\right) \mathrm{nm}$ with the solution changed from colorless to purple due to the formation of closed-ring isomer 1c. Reversely, the purple solution could be completely bleached upon illumination with visible light $(\lambda>500 \mathrm{~nm})$, indicating that 1c returned to the initial state $\mathbf{1 0}$ and a clear isosbestic point was observed. From the above description, we can easily get a conclusion that both open-ring isomer and closed-ring isomer of this diarylethene were stable in solution at room temperature.

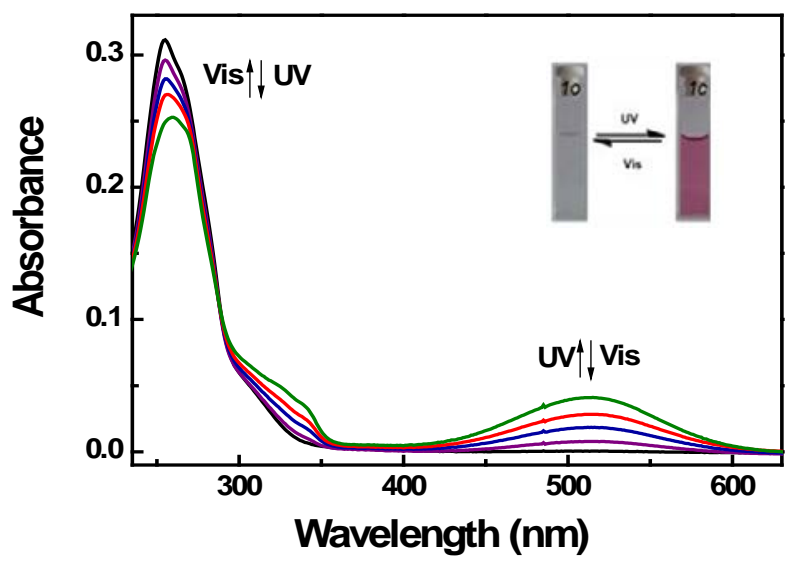

Fig. 1. Absorption spectra and color changes of $\mathbf{1 0}$ in hexane

\section{Photochromic Reaction Kinetics}

The photochromic cyclization and cycloreversion kinetics of $\mathbf{1 0}$ in hexane were determined by UV-Vis spectra upon alternating irradiation with UV and visible light at room temperature. The cyclization and cycloreversion curves of $\mathbf{1 0}$ were shown in Fig. 2. It can be seen that the relationships between the absorbance and exposal time have good linearity upon irradiation with $297 \mathrm{~nm}$ UV light. The results suggesting that the cyclization processes of $\mathbf{1 0}$ belong to the zeroth order reaction when open-ring isomer changed to closed-ring isomer. The slope of every line in Fig. 2 (A) and 2 (B) represents the reaction rate constant $(k)$ of diarylethene 10 in hexane. So all $k$ of cyclization $\left(k_{0-c}, 10^{-4}\right)$ / cycloreversion $\left(k_{\mathrm{c}-\mathrm{o}}, 10^{-4}\right)$ process of diarylethene 10 can be easily obtained, which are $2.2 \mathrm{~mol} \mathrm{~L}^{-1} \mathrm{~s}^{-1}$ and $10.1 \mathrm{~mol} \mathrm{~L}^{-1} \mathrm{~s}^{-1}$ in solution, respectively. 


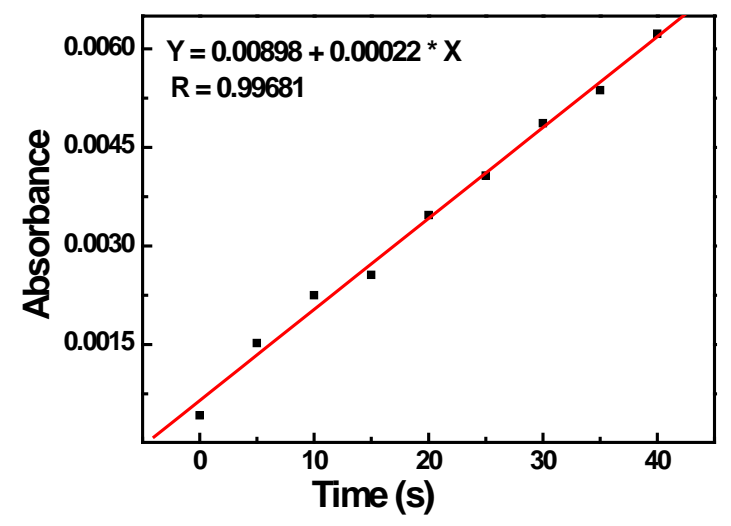

(A)

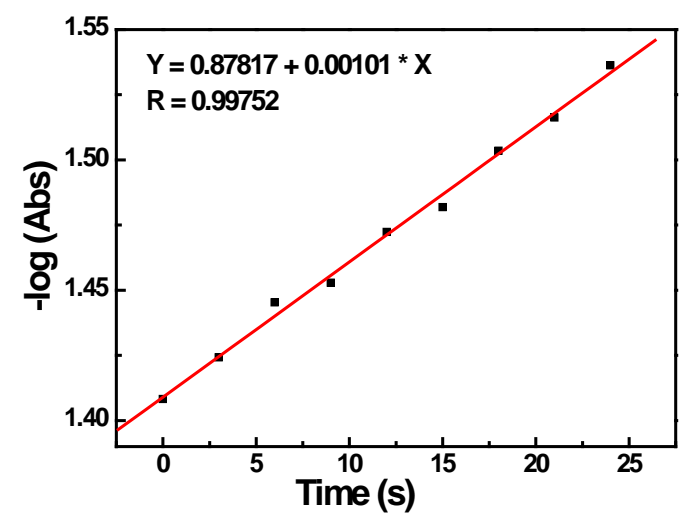

(B)

Fig. 2. The cyclization (A) and cycloreversion (B) kinetics of $\mathbf{1 0}$ in hexane.

\section{Fluorescence of 10}

The fluorescence emission spectra of 10 in hexane $\left(2.0 \times 10^{-5} \mathrm{~mol} \mathrm{~L}^{-1}\right)$ were evaluated at room temperature. The emission peak of 10 in hexane was observed at $441 \mathrm{~nm}$ when excited at $285 \mathrm{~nm}$ (Fig. 3). Upon irradiation with UV light, the emission intensity of $\mathbf{1 0}$ was decreased notably due to the formation of the weak fluorescent closed-ring isomer 1c. The back irradiation by visible light regenerated the open-ring isomer $\mathbf{1 0}$ and recovered the original emission spectra.

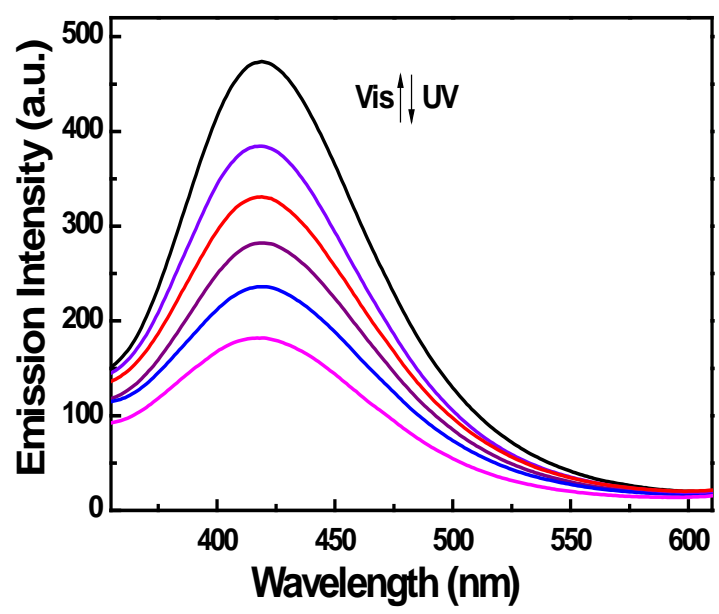

Fig. 3. Emission intensity changes of $\mathbf{1 0}$ upon irradiation UV at room temperature: in hexane

\section{Summary}

In summary, a novel photochromic diarylethene was synthesized. 1o exhibited good photochromism and notable fluorescence switch in hexane solution. The results are useful for the design of diarylethene with efficient and excellent characteristic.

\section{Acknowledgement}

This work was supported by the National Natural Science Foundation of China (51373072), the Project of Jiangxi Advantage Sci-Tech Innovative Team (20142BCB24012), the Science Funds of Jiangxi Science \& Technology Normal University (2014XJZD001). 


\section{References}

[1] M. Irie, Photo-Reactive Materials for Ultrahigh-Density Optical Memory, Elsevier, Amsterdam. 1994.

[2] C.J. Roxburgh, P.G. Sammes, On the acid catalysed isomerisation of some substituted spirobenzopyrans, Dyes. Pigm. 27 (1995) 63-69.

[3] X.Y. Zhao, M.Z. Wang, Deposition of plasma conjugated polynitrile thin films and their optical properties, Eur. Polym J. 42 (2006) 2161-2167.

[4] Y. Yokoyama, Fulgides for memories and switches, Chem. Rev. 100 (2000) 1717-1740.

[5] Q. Zou, J.Y. Jin, B. Xu, L. Ding, H. Tian, New photochromic chemosensors for $\mathrm{Hg}^{2+}$ and $\mathrm{F}^{-}$, Tetrahedron. 67 (2011) 915-921.

[6] M. Irie. Diarylethenes for memories and switches, Chem. Rev. 100 (2000) 1685-1716.

[7] H, Tian, S. Q. Yang, Recent progresses on diarylethene based photochromic switches, Chem. Soc. Rev. 33 (2004) 85-87.

[8] J.J. Zhang, Q. Zou, H. Tian, Search for dark matter candidates and large extra dimensions in events with a jet and missing transverse momentum with the ATLAS detector, Adv. Mater. 18 (2013) 378.

[9] S.Z. Pu, Z.P. Tong, G. Liu, R.J. Wang, Multi-addressable molecular switches based on a new diarylethene salicylal Schiff base derivative, J. Mater. Chem. C. 1 (2013) 4726-4739.

[10]T. Darwish, R. Evans, M. James, N. Malic, G. Triani, T. Hanley, $\mathrm{CO}_{2}$ Triggering and Controlling Orthogonally Multiresponsive Photochromic Systems, J. Am. Chem. Soc. 132 (2010) 10748-10755.

[11] Y.C. Jeong, J.P. Han, Y. Kim, E. Kim, S.I. Yang, K.H. Ahn, Characterization and photophysical properties of sulfur-oxidized diarylethenes, Tetrahedron. 63 (2007) 3173-3182.

[12]H. Shoji, D. Kitagawa, S. Kobatake, Alkyl substituent effects in photochemical and thermal reactions of photochromic thiophene-S, S-dioxidized diarylethenes, New J. Chem. 38 (2014) 933-941. 